\title{
Ten microsatellite loci for the strawberry poison frog (Oophaga pumilio)
}

\author{
J. Susanne Hauswaldt • Ann-Kathrin Ludewig • \\ Sabine Hagemann · Heike Pröhl $\cdot$ Miguel Vences
}

Received: 6 February 2009/Accepted: 11 February 2009/Published online: 25 February 2009

(C) Springer Science+Business Media B.V. 2009

\begin{abstract}
We describe primers and PCR conditions to amplify nine new tetranucleotide loci and one new dinucleotide locus isolated from the strawberry poison frog (Oophaga pumilio). In 21 individuals from Costa Rica, the number of alleles ranged from 4 to 16 , observed heterozygosities from 40 to $100 \%$, and polymorphic information content ranged from 0.60 to 0.90 per locus. Evidence for linkage disequilibrium was found only between two loci, but this pattern was not found in other populations tested. All primer pairs cross-amplified in Oophaga vicentei from Panama.
\end{abstract}

Keywords Amphibia - Anura - Dendrobatidae .

Microsatellite loci · Tetranucleotide $\cdot$ Dinucleotide

The distribution of the strawberry poison frog (Oophaga pumilio) ranges along the Caribbean lowlands of Central America, from Nicaragua across Costa Rica to northern Panama. Like other species of poison frogs (Dendrobatidae) it has a bright aposematic colouration. Unusual, however, is the colour polymorphism this species exhibits in the Bocas del Toro archipelago in northwestern Panama. While in

J. S. Hauswaldt $(\bowtie) \cdot$ A.-K. Ludewig $\cdot$ M. Vences

Unit of Evolutionary Biology, Institute of Zoology,

Technical University of Braunschweig, Spielmannstr. 8,

38106 Braunschweig, Germany

e-mail: s.hauswaldt@tu-bs.de

J. S. Hauswaldt

Max-Planck Institute for Evolutionary Biology, Plön, Germany

S. Hagemann · H. Pröhl

Institute of Zoology, University of Veterinary Medicine,

Hannover, Germany most part of the range, frogs are bright red on dorsal and ventral side with dark (black/blue) limbs, here its colour patterns are strikingly different and range from a yellow dorsal side with black spots and a white ventral side, to a dark green dorsal side with bright yellow venter. While colour patterns vary among sites, some locations even have striking variation within. Unfortunately, intensive development on some of these islands is threatening the habitat of several colour morphs.

Several phylogeographic studies have been carried out on $O$. pumilio, in particular to address populations from these islands (Hagemann and Pröhl 2007; Rudh et al. 2007; Wang and Shaffer 2008). However, the amount of colour polymorphism at Bocas del Toro still remains difficult to explain, although dorsal colouration appears to play a role in female preference (Maan and Cummings 2008). Fastevolving loci such as microsatellites may hold the key to decipher in more detail the genetic variation of this species, but so far such markers are unavailable for $O$. pumilio. We here report on the development of specific microsatellite markers for this species, aiming at loci with tetranucleotide motifs which we have found easier to score. For the enrichment, genomic DNA was used from an individual strawberry poison frog. DNA was enriched with two oligo mixtures containing tetranucleotide probes following the protocol by Glenn and Schable (2005). The mix of biotinylated oligonucleotides contained (AAGT) $)_{8},(\text { AGAT) })_{8}$, $(\mathrm{AACT})_{8},(\mathrm{ACAT})_{8}$, and $(\mathrm{AAAT})_{8}$ as probes. In brief, genomic DNA was digested with Rsa I, ligated to SuperSNX linkers, hybridized to the probes and captured with Dynabeads (Dynal Biotech Inc.). Unspecifically bound DNA was washed away according to the protocol and specifically bound DNA was recovered by PCR with the SuperSNX-f (5'-GTTTAAGGCCTAGCTAGCAGAATC-3') primer. PCR products were enriched twice. The resulting 
Table 1 Characterization of ten microsatellite loci for Oophaga pumilio. For $O$. p. number of alleles (NA), size ranges, observed (Ho), expected heterozygosity (He), and polymorphic information content
(PIC) are given for each locus. Size range refers to the observed distribution of alleles at each locus for $21 O . p$. and for two $O$. vicente $i$ $(O . v$.) (except for Oop_C3) all alleles found are listed

\begin{tabular}{|c|c|c|c|c|c|c|c|c|c|c|}
\hline Locus & Primer sequence $5^{\prime} \rightarrow 3^{\prime}$ & $\begin{array}{l}\text { Genbank } \\
\text { accession } \\
\text { number }\end{array}$ & $\begin{array}{l}\text { Repeat } \\
\text { sequence }\end{array}$ & $N$ & NA & $\begin{array}{l}\text { Size range } \\
\text { (bp) } O . p .\end{array}$ & $\begin{array}{l}\text { Alleles } \\
\text { (bp) } O . v .\end{array}$ & Ho & $\mathrm{He}$ & PIC \\
\hline Oop_C3-F & GGTCCTAACAACATGCACCTTTC & FJ645912 & $(\text { TATC })_{13}$ & 21 & 11 & $93-153$ & $129(\mathrm{~N}=1)$ & 1.0 & 0.88 & 0.84 \\
\hline Oop_C3-R & TCCAGCCTCCTCTTTTACATTTG & & & & & & & & & \\
\hline Oop_B8-F & TTTCCCATTAGAATGATTTTTGACTC & FJ645913 & $(\mathrm{TATC})_{11}$ & 21 & 11 & $294-338$ & $310,314,318,338$ & 0.76 & 0.87 & 0.83 \\
\hline Oop_B8-R & CTTGCTACACTTGATCCCAAACC & & & & & & & & & \\
\hline Oop_H5-F & GCGGAGAAGAAGGATGAAATAGC & FJ645914 & $(\text { TATC })_{17}$ & 21 & 13 & $258-314$ & $266,282,286$ & 0.67 & 0.92 & 0.88 \\
\hline Oop_H5-R & CCGGACTCTCCTTTTCTCTTACTG & & & & & & & & & \\
\hline Oop_B9-F & AAAATGTCCACCCATCATTTGTC & FJ645915 & $(\mathrm{TATC})_{21}$ & 21 & 10 & $136-176$ & $128,132,172$ & 0.67 & 0.89 & 0.85 \\
\hline Oop_B9-R & GAACAATTTGAAAGGATGCCAAC & & & & & & & & & \\
\hline Oop_F1-F & CGCAGTTTCCTATTGTCTTTTCC & FJ645916 & $(\mathrm{TAGA})_{19}$ & 21 & 16 & $308-372$ & $320,324,328$ & 0.86 & 0.93 & 0.90 \\
\hline Oop_F1-R & GGGCCAAAATCCTAACAAATTC & & & & & & & & & \\
\hline Oop_E3-F & AGACATGGCCATAACAAATGGAC & FJ645917 & $(\mathrm{TCTA})_{20}$ & 20 & 8 & $390-422$ & 386,398 & 0.40 & 0.77 & 0.72 \\
\hline Oop_E3-R & CATAGGGATATGCCTTGTTTGC & & & & & & & & & \\
\hline Oop_G5-F & CCATTGACTTACATTGGATTCG & FJ645918 & $(\mathrm{TATC})_{26}$ & 21 & 14 & $286-358$ & 306,334 & 0.86 & 0.92 & 0.89 \\
\hline Oop_G5-R & TCGGAACTGTTTGCTTTGC & & & & & & & & & \\
\hline Oop_01-F & ATACTGCGACCGCTGTGTATAG & FJ645921 & $(\mathrm{TG})_{13}$ & 21 & 4 & $178-190$ & 178,186 & 0.62 & 0.68 & 0.60 \\
\hline Oop_01-R & GACAGACAGACACACTCCCTTG & & & & & & & & & \\
\hline Oop_D4-F & GCAGGGGCGTCACAATAG & FJ645919 & $(\mathrm{TAGA})_{14}$ & 21 & 8 & $186-254$ & $202,210,234,254$ & 0.76 & 0.66 & 0.61 \\
\hline Oop_D4-R & CGCTAAAGGTCAGGTTTTGG & & & & & & & & & \\
\hline Oop_C11-F & TTGCGGTGGTCTCTTAATTTTTG & FJ645920 & $(\mathrm{TAGA})_{22}$ & 21 & 6 & $154-178$ & 162,178 & 0.52 & 0.68 & 0.62 \\
\hline Oop_C11-R & ATTCTTTACGAGTGGAGGGGTTG & & & & & & & & & \\
\hline
\end{tabular}

PCR products were cloned using the TOPO TA Cloning System (2.1) (Invitrogen). Colonies were amplified using M13 primers and for 50 colony-PCR products of 5001,000 base pairs good sequences were obtained with T3 and T7 primers. Sequencing was done using BigDye version 3.1 chemistry (Applied Biosystems) on an ABI 3730XL sequencer.

Sequences of 39 clones contained microsatellite motifs but in nine of these the motives were repeated less than nine times and they were not considered further. Two other clones contained composite microsatellites and one a dinucleotide locus, therefore neither were used for primer design. In five clones the flanking sequence was too short for successful primer design. Primers were designed for 19 loci with PRIMER3 version 0.4.0. For ten loci primers did not render amplicons of the appropriate size or generated more than two bands per individual. Primers for nine polymorphic tetranucleotide loci were identified (Table 1). A further dinucleotide locus had previously been isolated by one of us (SH). This was done using a modified protocol by Fischer and Bachman (1998) and the detailed procedure is described in Hagemann (2005).

Two quadruplex and one duplex PCR were performed using the Type-it Microsatellite PCR Kit (Qiagen). All reactions were done in volumes of $5 \mu \mathrm{l}$ and all primers were at $10 \mu \mathrm{M}$ concentrations. Forward and reverse primers for each locus were mixed at equal proportion, and these mixes were used for the following recipes. For the first multiplex mix $1.25 \mu \mathrm{l}$ Master Mix, $0.35 \mu \mathrm{l}$ of Oop_B8, $0.3 \mu \mathrm{l}$ of Oop_C3, $0.25 \mu \mathrm{l}$ of Oop_H5, and $0.15 \mu \mathrm{l}$ of Oop_01, $1 \mu \mathrm{l}$

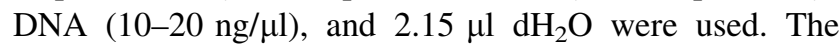
second mix contained the same amount of master mix and water, $0.3 \mu \mathrm{l}$ each of Oop_B9, Oop_F1, and Oop_E3 and $0.15 \mu$ of Oop_D4. Oop_G5 and Oop_C11 were amplified in a duplex reaction using $0.3 \mu$ of each primer mix. All reactions were performed using the same thermal cycling program: following an initial denaturation at $95^{\circ} \mathrm{C}$ for $5 \mathrm{~min}, 35$ cycles were run with: $95^{\circ} \mathrm{C}$ for $30 \mathrm{~s}, 60^{\circ} \mathrm{C}$ for $90 \mathrm{~s}$ and $72^{\circ} \mathrm{C}$ for $45 \mathrm{~s}$. This was followed by a $30 \mathrm{~min}$ extension at $60^{\circ} \mathrm{C}$. Amplicons were diluted appropriately before fragment size determination was done on an $\mathrm{ABI}$ 3130XL automated sequencer using LIZ 600 (Applied Biosystems) as an internal size standard and analysed using GENEMAPPER software (Applied Biosystems).

We genotyped 21 O pumilio individuals from Costa Rica. Because we did not have a large enough sample from one population, we combined samples from two sites, Guápiles $\left(\mathrm{N} 10^{\circ} 11.298^{\prime}{\mathrm{W} 83^{\circ}}^{\circ} 49.274^{\prime}\right)$ and Pueblo Nuevo (N10

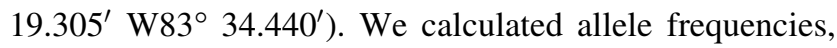
observed and expected heterozygosity, and polymorphic 
information content (PIC) values using CERVUS vs. 3.0 (Kalinowski et al. 2007). We further analysed the loci for deviation from Hardy-Weinberg Equilibrium and tested for linkage disequilibrium with GENEPOP web vs. 3.4 (Raymond and Rousset 1995). The results of testing the ten primer pairs on 21 Oophaga pumilio DNA samples are summarized in Table 1 . We detected an average number of 10.1 alleles per locus (range 4-16), an average observed heterozygosity of 0.71 (range $0.40-1.0$ ), and an average PIC of 0.77 (range 0.60-0.90). Linkage disequilibrium was detected between Oop_C3 and Oop_G5, but this pattern was not confirmed in other populations tested (data not shown). In the sample studied here, one locus (Oop_E3) was found to be deviating from Hardy-Weinberg equilibrium after Bonferroni correction. We also tested all primers on two individuals of Oophaga vicentei from Panama (Provincia de Veraguas and Provincia Coclé): all primers amplified and alleles were within the size range of $O$. pumilio.

We now have a set of codominant markers developed that may aid in resolving some of the questions regarding the population genetic structure of this species, for example, by comparing the level of genetic diversity among populations with different colour pattern and by assessing the amount of gene flow among populations.

Acknowledgments The first part of the microsatellite isolation process was performed while JSH was at the Unit of Evolutionary Genetics at the University of Cologne, and we thank Diethard Tautz for support. At Cologne, JSH has been supported by a postdoctoral fellowship from the Max-Planck Institute for Evolutionary Biology in Plön.

\section{References}

Fischer D, Bachman K (1998) Microsatellite enrichment in organisms with large genomes (Allium cepa L.). Biotechniques 24:796-802

Glenn TC, Schable NA (2005) Isolating microsatellite DNA loci. Methods Enzymol 395:202-222. doi:10.1016/S0076-6879(05) 95013-1

Hagemann S (2005) Genetische variation beim Erdbeerfröschchen (Dendrobates pumilio) in Costa Rica und Panama. Diploma Thesis, University of Veterinary Medicine, Hannover, 142 pp

Hagemann S, Pröhl H (2007) Mitochondrial paraphyly in a polymorphic poison frog species (Dendrobatidae; D. pumilio). Mol Phylogenet Evol 45:740-747. doi:10.1016/j.ympev.2007.06.010

Kalinowski ST, Taper ML, Marshall TC (2007) Revising how the computer program CERVUS accommodates genotyping error increases success in paternity assignment. Mol Ecol 16:10061099. doi:10.1111/j.1365-294X.2007.03089.x

Maan ME, Cummings ME (2008) Female preferences for aposematic signal components in a polymorphic poison frog. Evolution Int J Org Evolution 62:2334-2345. doi:10.1111/j.1558-5646.2008. 00454.x

Raymond M, Rousset F (1995) GENEPOP (version 1.2): population genetics software for exact tests and ecumenicism. J Hered 86:248-249

Rudh A, Rogell B, Höglund J (2007) Non-gradual variation in colour morphs of the strawberry poison frog Dendrobates pumilio: genetic and geographical isolation suggest a role for selection in maintaining polymorphism. Mol Ecol 16:4284-4294. doi:10.1111/ j.1365-294X.2007.03479.x

Wang IJ, Shaffer HB (2008) Rapid color evolution in an aposematic species: a phylogenetic analysis of color variation in the strikingly polymorphic strawberry poison-dart frog. Evolution Int J Org Evolution 62:2742-2759. doi:10.1111/j.1558-5646. 2008.00507.x 